\title{
EFEITO DE INDUTORES DE RESISTÊNCIA SOBRE Meloidogyne exigua DO CAFEEIRO
}

\author{
Effect of resistance inducers on Meloidogyne exígua of coffee
}

\author{
Sônia Maria de Lima Salgado ${ }^{1}$, Mário Lúcio Vilela Resende², Vicente Paulo Campos ${ }^{3}$
}

\begin{abstract}
RESUMO
A possibilidade de manejo de Meloidogyne exigua Goeldi, 1887, pela ativação de mecanismos de defesa no cafeeiro representa uma alternativa potencialmente útil no manejo desse patógeno. Com este trabalho, objetivou-se avaliar a eclosão e mortalidade de juvenis do segundo estádio (J2) de M. exigua na presença de produtos indutores de resistência e avaliar o efeito do acibenzolar-S-metil $\left(\right.$ ASM, Bion ${ }^{\circledast}$ ) na indução de resistência do cafeeiro (Coffea arabica L.) 'Catuaí- 144' contra M. exigua. A eclosão e mortalidade do J2 foram avaliadas no ASM e ácido salicílico (AS) nas dosagens de 0,$2 ; 0,35$ e 0,5 g. i. a./L; e no fosfito de potássio (Hortifós ${ }^{\circledR} \mathrm{PK}$ ) e silicato de potássio (Supa-potássio ${ }^{\circledR}$ ) nas dosagens 5,0; 7,5 e 10,0 mL/L, empregando água e aldicarbe como testemunhas. No segundo ensaio o $\operatorname{ASM}(0,2 \mathrm{~g}$ i.a./L) foi aplicado na quantidade de $125 \mathrm{~mL}$ por planta de 'Catuaí-144' com um ano de idade, via pulverização foliar e diretamente ao solo aos 7 dias antes da inoculação e aos 2 e 7 dias após a inoculação de aproximadamente 7000 ovos de $M$. exigua/planta. Foram utilizadas 8 plantas/tratamento/bloco, totalizando 6 tratamentos (3 épocas de aplicação do ASM), testemunhas absoluta e inoculada, em 4 blocos. Aos 90 dias da inoculação, foi feita a avaliação da população final (número de ovos e juvenis de $M$. exigua), número de galhas, fator de reprodução (população final/população inicial) e peso da matéria fresca da raiz. A dosagem dos produtos não influenciou a eclosão e mortalidade dos J2 de M. exigua. Menor eclosão dos J2 de M. exigua ocorreu igualmente no Supa-potássio ${ }^{\circledR}$ e ácido salicílico, enquanto que a eclosão no ASM e na água foi igual $(\mathrm{P} \leq 0,05)$ e significativamente menor que a eclosão dos $\mathrm{J} 2$ no Hortifós ${ }^{\circledR} \mathrm{PK}$. Maior mortalidade dos $\mathrm{J} 2$ ocorreu igualmente $(\mathrm{P} \leq 0,05)$ no ácido salicílico (AS) e no aldicarbe $(500 \mathrm{ppm})$. Os demais produtos causaram mortalidade igual e inferior àquela observada na água. Aos 90 dias da inoculação de M. exigua nas mudas, não houve diferença significativa entre os tratamentos para nenhuma das variáveis analisadas, quais sejam, população final (número de ovos $+\mathrm{J} 2$ ), número de galhas e fator de reprodução (população final/população inicial). As plantas tratadas com o ASM não diferiram significativamente da testemunha inoculada, e o peso da matéria fresca da raiz das plantas tratadas foi estatisticamente igual $(\mathrm{P} \leq 0,05)$ à testemunha absoluta.
\end{abstract}

Termos para indexação: Nematóide de galha, juvenis, mortalidade, eclosão, Coffea arábica.

\begin{abstract}
The parasitism of coffee roots by Meloidogyne exigua Goeldi, 1887, widespread nematode in the main producing regions, can provoke a series of modifications in the normal development of the plant. The induction of resistance for the activation of existing latent mechanisms of defense in plants represents a potentially useful alternative for the management of $M$. exigua in coffee plantations. In a first assay, the present work aimed at evaluating hatching and mortality of second stage juveniles (J2) of M. exigua in solutions of acibenzolar-S-metil (ASM, Bion ${ }^{\circledR}$ ) and salicylic acid (SA) at the dosages of 0.2, 0.35 and $0.5 \mathrm{~g}$. of a. i./L and Supapotássio ${ }^{\circledast}$ (potassium silicate), Hortifós ${ }^{\circledast} \mathrm{PK}$ (potassium phosphite) at the dosages 5.0; 7.5 and $10.0 \mathrm{~mL} / \mathrm{L}$, using water and aldicarb as control. The effect of $\operatorname{ASM}(0.2 \mathrm{~g}$ of a.i./L) was also evaluated by foliar and drench applications at 7 days before inoculation and at 2 and 7 days after inoculation of 7000 eggs of $M$. exigua/plant. The hatching of M. exigua $\mathbf{J} 2$ was inhibited in potassium silicate and in salicylic acid solutions independent of the used dosage, while J2 hatching in ASM and water was equal and significantly lower than J2 hatching verified in potassium phosphite. The mortality of J2 in SA was next to $100 \%$ and equal to the observed in aldicarb (500 $\mathrm{ppm}$ ). The remaining products caused the same mortality of $\mathrm{J} 2$, however lesser than the observed in water. At ninety days of the inoculation of $M$. exigua on seedlings, the final population (number of eggs $+\mathrm{J} 2$ ), number of galls, reproduction factor (final population/initial population) and fresh weight of roots of plants treated with ASM did not differed significantly from control (inoculated plants).
\end{abstract}

Index terms: Root-knot nematode, juveniles, mortality, hatching, Coffea Arabica.

(Recebido em 7 de junho de 2005 e aprovado em 25 de maio de 2006)

\section{INTRODUÇÃO}

Meloidogyne exigua Goeldi, 1887 é um nematóide comumente encontrado na América Central e do Sul, onde causa perdas severas na produção cafeeira (CAMPOS \& VILLAIN, 2005). Estimativas de perdas causadas por $M$. exigua em lavouras cafeeiras são poucas. Barbosa et al. (2004) verificaram que lavouras bem conduzidas (nível tecnológico I) tiveram a sua produtividade comprometida por níveis populacionais de $M$. exigua a partir de três J2/ $100 \mathrm{~cm}^{3}$. de solo. Análise criteriosa de lavouras infestadas mostra que o parasitismo desse nematóide é altamente

${ }^{1}$ Pesquisadora do Centro Tecnológico do Sul de Minas - CTSM - Cx. P. 176 - Campus da UFLA - 37200-000 - Lavras, MG - soniamaria@epamig.br 2Professor Adjunto Departamento de Fitopatologia da Universidade Federal de Lavras/UFLA - Cx. P. 3037 - 37200-000 - Lavras, MG - mlucio@ufla.br 3Professor Titular de Fitopatologia da Universidade Federal de Lavras/UFLA - Cx. P. 3037 - 37200-000 - Lavras, MG - vpcampos@ufla.br 
prejudicial à produção cafeeira. Santos (1978) verificou alterações no estado nutricional do cafeeiro parasitado por M. exigua, decorrente da deficiente absorção e translocação de água e nutrientes.

A redução da população de $M$. exigua em lavouras infestadas, por meio de medidas ambientalmente aceitáveis, torna-se um grande desafio. Pelo fato de $M$. exigua permanecer internamente nas raízes do cafeeiro por várias semanas, onde estabelece seu sítio permanente de alimentação, se desenvolve e reproduz, esse nematóide passa grande parte de sua vida em local muitas vezes distante do sítio de aplicação de produtos nematicidas. Além disso, os nematicidas tradicionais, são voláteis e altamente tóxicos a outros organismos, representando um risco à segurança humana e ambiental, tal como a contaminação do lençol freático, além dos prejuízos à camada de ozônio na atmosfera. Desse modo há uma crescente necessidade de novos métodos de proteção do cafeeiro que sejam ambientalmente mais aceitáveis. Isso tem estimulado as pesquisas com resistência induzida como um método promissor de proteção da cultura, o qual em combinação com medidas convencionais pode contribuir para o controle de fitodoenças (LYON \& NEWTON, 1997).

Alguns produtos têm sido testados como indutores de resistência contra fitonematóides, entre eles o ácido salicílico (AS) na indução de resistência contra Meloidogyne incognita (Kofoid \& White) Chitwood, 1949, em Vigna catjang Walp. (NANDI et al., 2002) e o BABA, ácido DL- $\beta$-amino- $n$-butírico (OKA \& COHEN, 2001).

Um dos indutores químicos mais testados contra fitonematóides é o acibenzolar-S-metil (ASM). Owen et al. (1998) avaliaram o efeito do ASM na indução de resistência contra Meloidogyne javanica (Treub) Chitwood e $M$. arenaria (Neal) Chitwood, em videira. Nesse estudo, foi constatado que o ASM, aplicado via pulverização foliar, sete dias antes da inoculação, promoveu reduções de 40 a $80 \%$ no número de galhas e ovos em relação à testemunha. A resposta de defesa da planta foi verificada pelo aumento significativo na atividade de $\beta$-1,3-glucanases em raízes de plantas tratadas com ASM, cinco dias após a aplicação desse indutor. No patossistema Meloidogyne incognita tomateiro, a aplicação prévia do ASM antes da inoculação promoveu reduções significativas no número de galhas, massas de ovos e ovos/g raiz em relação ao controle. Nesse estudo, o ASM possivelmente interferiu na formação de células gigantes, por meio de alguma proteína essencial à formação das mesmas, o que afetou a reprodução do nematóide (SILVA et al., 2002a).
Além do ASM, outros produtos como fosfito e silicatos têm sido testados na indução de defesa de plantas a patógenos. Smillie et al. (1989) sugerem que plantas tratadas com fosfito seriam capazes de produzir compostos antimicrobianos de forma mais efetiva que as não tratadas. Jackson et al. (2000) mostraram que, dependendo da concentração, o fosfito pode induzir resistência em eucalipto contra Phytophthora cinnamomi Rands. O fosfito é liberado pela hidrólise do etil fosfonato, conferindo à planta proteção contra fungos patogênicos (MCDONALD, 2001), o que parece ocorrer com o fosfito de potássio (FENN \& COFFEY, 1989; NIERE et al., 1994).

São comuns trabalhos comprovando a ação do silício no controle de algumas doenças em plantas (NOJOSA et al., 2005). Quanto aos silicatos, há evidências de que o envolvimento na indução de resistência pode ocorrer pela participação do próprio silício, fortalecendo estruturas das paredes celulares e ativação de mecanismos específicos (FAWE et al., 2001; MENZIES et al., 1991).

Tratando-se de indução de resistência contra fitonematóides, não há restrições se a cultura é anual ou perene, porém alguns fatores devem ser considerados, entre eles, a natureza da interação no patossistema específico; a genética da planta hospedeira; a necessidade de reativação dos mecanismos de defesa tendo em vista o efeito temporário do indutor.

A ausência de efeito tóxico direto do agente indutor sobre o patógeno desafiante está entre os critérios básicos para confirmação da ocorrência de resistência induzida. Diante disso e da necessidade de uma alternativa de controle de Meloidogyne exigua do cafeeiro, este trabalho teve como objetivo avaliar a eclosão e mortalidade de juvenis de segundo estádio (J2) de M. exigua no acibenzolar-S-metil, ácido salicílico (AS), fosfito de potássio e silicato de potássio e induzir resistência em mudas de cafeeiro (Coffea arabica L.) cultivar 'Catuaí 144' contra $M$. exígua.

\section{MATERIAL E MÉTODOS}

Experimento 1: Eclosão e mortalidade de juvenis do segundo estádio (J2) de M. exigua em indutores químicos de resistência.

Ovos e $\mathbf{J} 2$ de $M$. exigua foram obtidos de raízes de cafeeiros com galhas mantidos em casa-de-vegetação para multiplicação do inóculo. Os ovos foram extraídos pelo método de Hussey \& Barker (1973). Parte da suspensão de ovos foi mantida em incubação em câmaras de eclosão 
preparadas em funil de Baermann, de onde os $\mathrm{J} 2$ eclodidos foram diariamente coletados.

Em câmaras de eclosão montadas em placas de Petri $(4,5 \mathrm{~cm})$ conforme descrito por Salgado \& Campos (2003), colocaram-se aproximadamente 700 ovos de $M$. exigua e 5 $\mathrm{mL}$ dos indutores acibenzolar-S-metil (ASM, Bion ${ }^{\circledR}$ Syngenta Proteção de Cultivos Ltda, São Paulo, SP) e ácido salicílico (AS, $\mathrm{C}_{7} \mathrm{H}_{6} \mathrm{O}_{3}$, Merck $^{\circledR}$ ) nas dosagens de $0,2 \mathrm{~g} / \mathrm{L}$; $0,35 \mathrm{~g} / \mathrm{L}$ e $0,5 \mathrm{~g} / \mathrm{L}$ e silicato de potássio-20\% $\mathrm{SiO}_{2}$ (Supapotássio $^{\circledR}$, Agrichem do Brasil Ltda, Ribeirão Preto, SP), fosfito de potássio-20\% $\mathrm{P}_{2} \mathrm{O}_{5}+27 \% \mathrm{~K}_{2} \mathrm{O}$ (Hortifós ${ }^{\circledR} \mathrm{PK}$, Agrichem do Brasil Ltda, Ribeirão Preto, SP) nas dosagens de 5,0 mL/L; 7,5 mL/L e 10,0 mL/L. O ensaio foi montado em delineamento inteiramente casualizado, em esquema fatorial com 4 indutores e 3 dosagens, empregando-se água como testemunha, totalizando 13 tratamentos em 4 repetições. Aos 15 dias de incubação dos ovos nos indutores, em temperatura de $20-25^{\circ} \mathrm{C}$, avaliou-se a porcentagem de $\mathrm{J} 2$ eclodidos. Os dados foram analisados pelo programa Sisvar 4.3 , mediante transformação para $\log (\mathrm{x})$. As diferenças estatísticas foram detectadas pelo teste Scott \& Knott (1974) a 5\% de significância.

A mortalidade dos $\mathrm{J} 2$ de $M$. exigua nos indutores foi feita empregando-se lâminas escavadas com $120 \mu \mathrm{L}$ dos indutores nas mesmas dosagens do ensaio de eclosão. Cada lâmina recebeu aproximadamente 15 indivíduos J2 eclodidos nas últimas 24 horas. Esse ensaio foi instalado em blocos casualizados, com 4 indutores em 3 dosagens, e teve como testemunhas o aldicarbe (500 ppm) e água. Empregaram-se 3 repetições representadas pela média de 3 unidades amostrais. Mantiveram-se as lâminas em câmara úmida preparada com placa de Petri $(90 \mathrm{~mm}$ ) forrada com papel umedecido. Com 24 horas da imersão dos J2 nos indutores, avaliou-se a porcentagem de juvenis eclodidos pela técnica de Chen \& Dickson (2000) e os dados foram analisados pelo programa estatístico Sisvar 4.3 e as diferenças estatísticas verificadas pelo teste de Scott \& Knott (1974).

\section{Experimento 2: Efeito do ASM contra M. exigua em mudas de cafeeiro}

\section{Preparo das mudas de cafeeiro}

Mudas de cafeeiro, Coffea arabica cultivar 'Catuaí 144' foram obtidas do viveiro comercial local, certificado pelo Instituto Mineiro de Agropecuária, IMA. As mudas foram produzidas em mistura 5:2 de solo e esterco, suplementado com cloreto de potássio e superfosfato simples. Quando as mudas atingiram o estágio de "orelhade-onça", aproximadamente seis meses após o plantio, foram selecionadas as mais vigorosas e mantidas em casade-vegetação até atingirem 18 meses de idade para utilização no experimento.

\section{Obtenção de ovos de Meloidogyne exigua}

De raízes galhadas de cafeeiros infectados, mantidos para multiplicação de $M$. exigua em casa-devegetação, extraíram-se os ovos pela técnica de Hussey \& Barker (1973). A seguir, a suspensão de ovos foi quantificada e calibrada para aproximadamente 1700 ovos/mL.

\section{Efeito do ASM na proteção de mudas de cafeeiro Catuaí- 144 contra Meloidogyne exigua}

$\mathrm{O}$ produto comercial à base de acibenzolar-S-metil $\left(\right.$ Bion $^{\circledR}$ ) foi aplicado na dosagem de $0,2 \mathrm{~g}$ i.a./L $(125 \mathrm{~mL} /$ planta), via pulverização foliar e molhamento do solo, aos sete dias antes da inoculação, e aos 2 e 7 dias após a inoculação de 7000 ovos de $M$. exigua/planta.

$\mathrm{O}$ experimento foi instalado em delineamento em blocos casualizados em casa-de- vegetação, com seis tratamentos constituídos de 3 épocas de aplicação de ASM, além de três tratamentos adicionais, formados por plantas inoculadas com $M$. exigua $\left(\mathrm{T}_{M e}\right)$, plantas tratadas com ASM e não inoculadas $\left(\mathrm{T}_{\mathrm{ASM}}\right)$ e plantas sem tratamento e sem inoculação $\left(\mathrm{T}_{\mathrm{ABS}}\right)$. Empregaram-se quatro repetições e cada parcela foi representada por 6 plantas (unidades amostrais).

Aos 90 dias da inoculação foi feita a avaliação da população final (número de ovos e juvenis de M. exigua), número de galhas, fator de reprodução (população final/ população inicial) e peso da matéria fresca da raiz. Como dado observado considerou-se a média das 6 unidades amostrais e a análise estatística foi realizada no programa SISVAR 4.3.

\section{RESULTADOS E DISCUSSÃO}

Experimento 1: Eclosão e mortalidade de juvenis do segundo estádio (J2) de M. exigua em indutores químicos de resistência.

As dosagens dos indutores não influenciaram $(\mathrm{P} \leq 0,05)$ a eclosão de $M$. exigua e não houve efeito significativo $\left(\mathrm{P}_{\leq} 0,05\right)$ da interação entre dosagem e produto. Menor eclosão de $M$. exigua ocorreu igualmente $(\mathrm{P} \leq 0,05)$ no silicato de potássio (Supa-potássio $\left.{ }^{\circledR}\right)$ e ácido salicílico (AS), Figura 1. A eclosão dos J2 em água foi estatisticamente igual $\left(\mathrm{P}_{\leq} 0,05\right)$ a eclosão no ASM, demonstrando a ausência de efeito inibitório do ASM na eclosão de $M$. exigua. Por outro lado, a eclosão de $M$. exigua em fosfito de potássio foi superior à eclosão na 
água. Nesse caso, acredita-se que o fosfito de potássio (Hortifós ${ }^{\circledR}-\mathrm{PK}$ ) tenha estimulado o desenvolvimento embrionário e/ou a saída do J2 do ovo. A alta eclosão de M. exigua no fosfito de potássio indica o potencial desse produto como estimulador da eclosão em solos preparados para culturas anuais, podendo estimular a eclosão de fitonematóides na ausência das plantas hospedeiras e conseqüentemente reduzir o inóculo inicial antes do plantio da lavoura.

O silicato de potássio apresentou efeito prejudicial apenas à eclosão dos J2 de M. exigua (Figura 1) já que esse efeito não foi observado aos juvenis (Figura 2), pois o número de $\mathrm{J} 2$ ativos nesse produto foi igual $\left(\mathrm{P}_{\leq} 0,05\right)$ ao controle (água). Nesse caso não ocorreu efeito inibitório ao desenvolvimento embrionário dos juvenis dentro dos ovos.

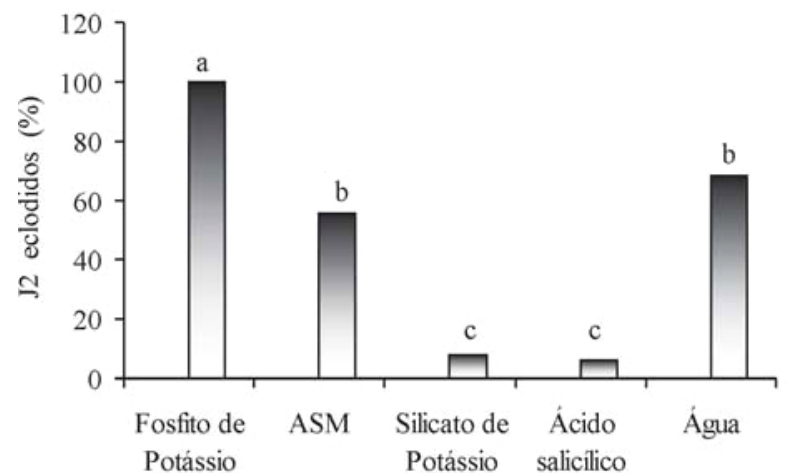

FIGURA 1 - Eclosão de juvenis do segundo estádio (J2) de Meloidogyne exigua em indutores químicos de resistência. Barras indicadas pela mesma letra não diferem estatisticamente $\left(\mathrm{P}_{\leq} 0,05\right)$ pelo teste Scott \& Knott (1974).

Alta mortalidade dos J2 ocorreu no AS, que foi estatisticamente igual à mortalidade observada no aldicarbe (Figura 2). Isso demonstra o efeito altamente tóxico do AS sobre M. exigua. O AS também exibiu alta toxicidade a $M$. incognita quando empregado na dosagem de $50 \mathrm{mg} / \mathrm{mL}$ (CHITWOOD, 2002; MAHESHWARI \& ANWAR, 1990).

Os produtos fosfito de potássio, silicato de potássio e ASM não apresentaram efeito tóxico aos J2 de M. exigua, verificado pelo número de $\mathrm{J} 2$ vivos que foi estatisticamente igual $\left(\mathrm{P}_{\leq} 0,05\right)$ a água (Figura 2$)$. Como ocorreu no ensaio de eclosão, não houve efeito significativo da dosagem e da interação dosagem $x$ indutores na mortalidade de $\mathrm{J} 2$.

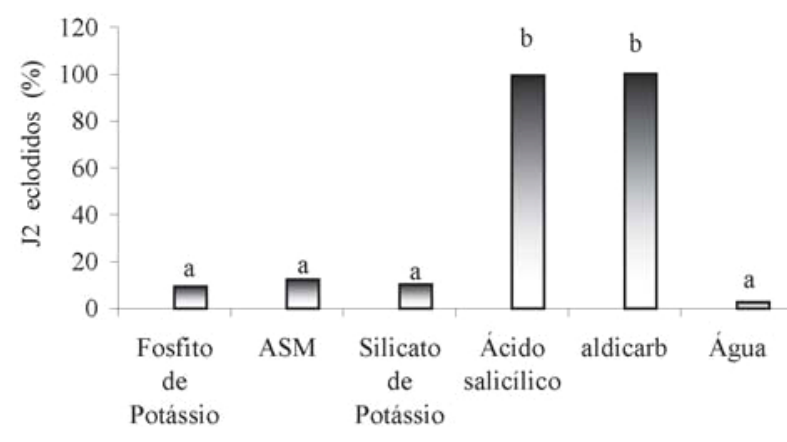

FIGURA 2 - Mortalidade de juvenis do segundo estádio (J2) de Meloidogyne exigua em indutores de resistência. Barras indicadas pela mesma letra não diferem estatisticamente $\left(P_{\leq} 0,05\right)$ pelo teste Scott \& Knott (1974).

\section{Experimento 2: Efeito do ASM sobre M. exigua em mudas de cafeeiro}

A ausência de efeito tóxico direto do ASM sobre M. exigua, verificado pela mortalidade e eclosão dos juvenis do segundo estádio comparado à testemunha água (experimento 1), determinou que apenas esse produto fosse aplicado nas plantas como agente indutor, buscando assim seguir um dos critérios básicos citados por Bonaldo et al. (2005) para real ocorrência de resistência induzida que é a ausência de toxicidade direta sobre patágeno.

A aplicação do ASM, independente da época, não diferiu $\left(\mathrm{P}_{\leq} 0,05\right)$ da testemunha inoculada, em todas as variáveis analisadas, quais sejam, número de galhas, fator de reprodução e população de $M$. exigua nas raízes. Um dos fatores que pode ter influenciado nesse resultado foi ouso de inóculo de M. exigua. Em diferentes estádios de embriogênese, o que possibilitou a eclosão dos juvenis ao longo do tempo de condução do experimento pois conforme visto anteriormente (Figura 1) o ASM não prejudica a eclosão dos juvenis. Talvez, a utilização de inóculo constituído de juvenis (J2) seria mais indicada já que a fase de penetração e início da formação do sítio de alimentação do nematóide nas raízes poderia coincidir com a fase de máximo efeito do ASM. Além disso, em lavoura cafeeira, normalmente a população de $M$. exigua é constituída de ovos, juvenis e adultos, e desse modo o 
emprego de inóculo constituído de J2 poderia representar uma situação mais próxima do que ocorre com a população no campo.

Devido à escassez de trabalhos com indução de resistência de plantas contra nematóide, conhecimentos sobre a melhor época de aplicação e dosagem do indutor não estão disponíveis. Além disso, os poucos trabalhos com indução de resistência (IR) de plantas contra fitonematóides apresentam resultados contraditórios. Silva et al. (2002b) observaram redução no número de galhas e massas de ovos de Meloidogyne sp. em tomateiro, mediante à aplicação do ASM a cada 7 dias, empregando inóculo constituído somente de ovos. A aplicação do ASM $(30 \mathrm{~g} / \mathrm{ha}-\mathrm{L})$ em cevada causou um aumento significativo na infecção de Pratylenchus sp. possivelmente por alguma modificação no exsudato radicular e/ou na morfologia da raiz, favorecendo a atração e invasão do nematóide (SONNEMANN et al., 2002). De acordo com Silva et al. (2002a), reduções significativas no número de galhas de Meloidogyne sp. em tomateiro ocorreram após a aplicação do ASM (2,5 g i.a./100L de água), via irrigação ou pulverização foliar. Entretanto, com a aplicação do ASM 14 dias após a inoculação de Meloidogyne sp.; não houve diferença significativa no número de ovos e massas de ovos/g de raiz. Isso demonstra a variação que pode ocorrer na planta com a aplicação de um tratamento indutor. Segundo Uknes et al. (1996), cada interação nematóideplanta deve possuir um período próprio, necessário para a sinalização e a conseqüente ativação de genes de defesa da planta.

Outra possível explicação para a ausência de efeito do ASM detectada no presente trabalho refere-se à rota de sinalização para indução de defesa do cafeeiro contra $M$. exigua. Sabe-se que o ASM possui ação semelhante ao ácido salicílico (AS). Há indicações que a resistência sistêmica adquirida (SAR) é dependente do AS e a resistência sistêmica induzida (ISR) é dependente do ácido jasmônico (JA) e etileno (ET), e ambas as reações de resistência são reguladas por rotas de sinalização distintas. Em muitos casos, plantas com infecção causada por alguns patógenos e ataque de insetos herbívoros apresentam aumento na produção dos hormônios JA e ET, concomitante com a ativação de genes de defesa (PIETERSE et al., 2004). Nesse contexto, acredita-se que a rota de sinalização para indução de resistência do cafeeiro contra $M$. exigua seja independente do AS e por isso cafeeiros tratados com ASM (0,2 g i.a/ L) não foram protegidos contra M. exigua. Siddiqui \& Shaukat (2004) verificaram que a resistência sistêmica induzida (ISR) em tomateiro contra Meloidogyne javanica ocorreu numa rota de transdução de sinal independente do acúmulo de ácido salicílico (AS) nas raízes. Diante disso, possivelmente, a rota de sinalização que induz resistência de plantas contra fitonematóides seja dependente do JA e ET. Para comprovação dessa hipótese são necessários trabalhos mais criteriosos, considerando o patossistema nematóideplanta número de aplicações do ASM e estudo da melhor época de aplicação para desencadear a provável ação indutora do produto durante a fase de penetração e desenvolvimento do M. exigua no cafeeiro.

\section{CONCLUSÕES}

Dos indutores testados, apenas o ASM não interferiu na eclosão e mortalidade in vitro dos juvenis J2 de Meloidogyne exigua, demonstrando que esse produto não possui efeito tóxico direto.

Não houve efeito indutor contra $M$. exigua nas mudas de cafeeiro tratadas com ASM.

\section{AGRADECIMENTOS}

À Fundação de Amparo à Pesquisa do Estado de Minas Gerais - FAPEMIG, pela concessão de bolsa à Sônia Maria de Lima Salgado e apoio na realização do trabalho.

\section{REFERÊNCIAS BIBLIOGRÁFICAS}

BARBOSA, D. H. S. G.; VIEIRA, H. D.; SOUZA, R. M.; VIANA, A. P.; SILVA, C. P. Field estimates of coffee yield losses and damage threshold by Meloidogyne exigua. Nematologia Brasileira, Campinas, v. 28, n. 1, p. 49-54, 2004.

BONALDO, S. M.; PASCHOLATI, S. F.; ROMEIRO, R. S. Indução de resistência: noções básicas e perspectivas. In: CAVALCANTI, L.; SOUZA; DI-PIERO, R. M.; PASCHOLATI, S. F.; RESENDE, M. L. V. de; ROMEIRO, R. da $S$. (Eds.). Indução de resistência em plantas a patógenos e insetos. Piracicaba: FEALQ, 2005. 263 p.

CAMPOS, V. P.; VILLAIN, L. Nematodes parasites of coffee and cocoa. In: LUC, M.; SIKORA, R. A.; BRIDGE, J. (Eds.). Plant parasitic nematodes in subtropical and tropical agriculture. London: CAB International, 2005. p. 529-579.

CHEN, S. Y.; DICKSON, D. W. A technique for determining live second-stage juveniles of Heterodera glycines. Journal of Nematology, College Park, v. 32, n. 1, p. 117$121,2000$. 
CHITWOOD, D. J. Phytochemical based strategies for nematode control. Annual Review of Phytopathology, Palo Alto, p. 221-249, 2002.

FAWE, A.; MENZIES, J. G.; CHERIF, M.; BÉLANGER, R. R. Silicon and disease resistance in dicotyledons. In: DATNOFF, L. E.; SNYDER, G. H.; KORNDÖRFER, G. H (Eds.). Silicon in agriculture. Netherlands: Elsevier Science, 2001. p. 159-169.

FENN, M. E.; COFFEY, M. D. Quantification of phosphonate and ethyl phosphonate in tobacco and tomato tissues and significance for the mode of action of two phosphonate fungicides. Phytopathology, Saint Paul, v. 79, p. 76-82, 1989.

HUSSEY, R. S.; BARKER, R. K. A comparison of methods of collecting inocula of Meloidogyne spp.: including a new technique. Plant Disease Reporter, Washington, v. 57, p. 1025-1028, 1973

JACKSON, T. J.; BURGESS, T.; COLQUHOUN, I.; HARDY, G. E. S. Action of the fungicide phosphate on Eucalyptus marginata inoculated with Phytophthora cinnamomi. Plant Pathology, Honolulu, v. 49, p. 147-154, 2000.

LYON, G. D.; NEWTON, A. C. Do resistance elicitors offer new opportunities in integrated disease control strategies? Plant Pathology, Honolulu, v. 46, p. 636-641, 1997.

MAHESHWARI, D. K.; ANWAR, M. Nematicidal activity of some phenolics on root knot, growth and yield of Capsicum frutescens cv. California Wonder. Journal of Phytopathology, [S.1.], v. 129, n. 2, p. 159-164, 1990.

McDONALD, A. E.; GRANT, B. R.; PLAXTON, W. C. Phosphite (phosphorus acid): its relevance in the environment and agriculture and influence on plant phosphate starvation response. Journal of Plant Nutrition, Monticello, v. 24, p. 1505-1519, 2001.

MENZIES, J. G.; EHRET, D. L.; GLASS, A. D. M.; HELMER, T.; KOCH, C.; SEYWERD, F. Effects of soluble silicon on the parasitic fitness of Sphaerotheca fugilinea on Cucumis sativus. Phytopathology, Palo Alto, v. 81, p. 84-88, 1991.

NANDI, B.; SUKUL, N. C.; BANERJEE, N.; SENGUPTA, S.; DAS, P.; BABU, S. P. S. Salicylic acid enhances resistance in cowpea against Meloidogyne incognita. Phytopathologia Mediterranea, [S.1.], v. 41, p. 39-44, 2002.

NIERE, J. O.; DEANGELIS, G.; GRANT, B. R. The effect of phosphonate on acid-soluble phosphorus components in the genus Phytophthora. Microbiology, [S.1.], v. 140, p. 1661-1670, 1994.

NOJOSA, G. B. de A.; RESENDE, M. L. V.; RESENDE, A. V. Uso de fosfitos e silicatos na indução de resistência. In: CAVALCANTI, L.; SOUZA; DI-PIERO, R. M.; PASCHOLATI, S. F.; RESENDE, M. L. V. de; ROMEIRO, R. da $S$. (Eds.). Indução de resistência em plantas a patógenos e insetos. Piracicaba: FEALQ, 2005. 263 p.

OKA, Y.; COHEN, Y. Induced resistance to cyst and rootknot nematodes in cereals by DL-b-amino-butyric acid. European Journal of Plant Pathology, London, v. 107, p. 219-227, 2001.

OWEN, K. J.; GREEN, C. D.; DEVERALL, B. J. Systemic acquired resistance against root-knot nematodes in grapevines. In: INTERNATIONAL CONGRESS OF PLANT PATHOLOGY, 7., 1998, Edinburg, UK. Proceedings... Edinburg: [s.n.], 1998.

PIETERSE, C. M. J.; PELT, J. A. van; WEES, S. C. M. van; TON, J.; VERHAGEN, B. W. M.; LÉON-KLOOSTERZIEL, K.; HASE, S.; VOS, M. de; OOSTEN, V. V.; POZO, M.; SPOEL, S.; ENT, A. van der; KOORNNEEF, A.; LOON, L. C. van. Rhizobacteria-induced systemic resistance and pathway cross talk to fine-tune defense. In: REUNIÃO BRASILEIRA SOBRE INDUÇÃO DE RESISTÊNCIA EM PLANTAS, 2.; SIMPÓSIO DE CONTROLE DE DOENÇA DE PLANTAS, 4., 2004, Lavras. Anais... Lavras: UFLA, 2004. p. 44-58.

SALGADO, S. M. L.; CAMPOS, V. P. Eclosão e mortalidade de Meloidogyne exigua em extratos e em produtos naturais. Fitopatologia Brasileira, Brasília, v. 28, p. 166-170, 2003.

SANTOS, J. M. dos. Efeitos de fertilizantes sobre Meloidogyne exigua e influência de seu parasitismo sobre a absorção e translocação de nutrientes em mudas de Coffea arabica L. Viçosa: UFV, 1978. 49 p.

SCOTT, A. J.; KNOTT, M. Cluster analysis method for grouping means in the analysis of variance. Biometrics, Washington, v. 30, p. 507-512, 1974. 
SIDDIQUI, I. A.; SHAUKAT, S. S. Systemic resistance in tomato induced by biocontrol bacteria against the rootknot nematode, Meloidogyne javanica is independent of salicylic acid production. Journal of Phytopathology, [S.1.], v. 152, p. 48-54, 2004.

SILVA, L. H. C. P.; CAMPOS, J. R.; CAMPOS, V. P.; DUTRA, M. R. Época de aplicação do acibenzolar-S-metil e da abamectina no controle de Meloidogyne sp. em tomateiro. Fitopatologia Brasileira, Brasília, v. 27, p. 194, 2002a.

SILVA, L. H. C. P.; CAMPOS, J. R.; CAMPOS, V. P.; DUTRA, M. R. Efeito do acibenzolar-S-metil (ASM) e da abamectina na proteção de cultivares de tomateiro contra Meloidogyne sp. Fitopatologia Brasileira, Brasília, v. 27, p. 195, 2002b.
SMILLIE, R.; GRANT, B. R.; GUEST, D. The mode of action of phosphate: evidence for both direct and indirect modes of action on three Phytophthora spp. in plants. Phytopathology, Saint Paul, v. 79, p. 921-926, 1989.

SONNEMANN, I.; FINKHAEUSER, K.; WOLTERS, V. Does induced resistance in plants affect the belowground community? Applied Soil Ecology, [S.1.], v. 21, p. 179-185, 2002.

UKNES, S.; VERNOIJ, B.; MORRIS, S.; CHANDLER, D.; STEINER, H.; SPECKER, N.; HUNT, M.; NEUENSCHWANDER, U.; LAWTON, K.; STARRET, M.; FRIEDRICH, L.; WEIMANN, K.; NEGROTTO, D.; GÖRLACH, J.; LANAHAN, M.; SALMERON, J.; WARD, E.; KESSMANN, H.; RYALS, J. Reduction of risk for growers: methods for the development of disease-resistance crops. New Phytologist, Cambridge, v. 133, p. 3-10, 1996. 